\title{
EDUCAÇÃO E RESISTÊNCIA CAMPONESA NA AMAZÔNIA
} PARAENSE

\author{
EDUCATION AND PEASANT RESISTANCE IN THE PARAENSE \\ AMAZONIA
}

\section{EDUCACIÓN Y RESISTENCIA CAMPESINA EN LA AMAZONIA PARAENSE}

\section{Chirles da Silva Monteiro}

Mestre em Agriculturas Familiares e Desenvolvimento Sustentável e Especialista em Educação do Campo pela Universidade Federal do Pará - UFPA. Professora efetiva da Rede Pública Estadual do Pará e Municipal de Goianésia do Pará. chirles.monteiro@gmail.com / http://orcid.org/0000-0002-4267-0358

\section{Gutemberg Armando Diniz Guerra}

Graduado em Engenharia Agronômica pela Universidade Federal da Bahia - UFBA. Mestre em Desenvolvimento Sustentável do Trópico Úmido pela Universidade Federal do Pará - UFPA.

Doutor em Socioeconomia do Desenvolvimento (EHESS, França). Professor Associado Aposentado da Universidade Federal do Pará - UFPA. gguerra@ufpa.br / http:/ /orcid.org/0000-0002-8122-1141

Recebido: 30/12/2019; Aceito: 24/05/2021; Publicado: 11/10/2021.

\section{RESUMO}

Este artigo é fruto dos apontamentos da pesquisa de mestrado desenvolvida no Programa de PósGraduação em Agriculturas Amazônicas (PPGAA) da Universidade Federal do Pará - UFPA. Aborda os desafios da luta pela terra no Sudeste Paraense, refletindo sobre o papel da educação nesse processo. Ele aponta a educação que permeia o cotidiano das pessoas, como elemento que fortalece a resistência política dos camponeses, por isso, não está apenas relacionada à conquista da terra, mas também, à permanência na mesma e à mudança da qualidade de vida nos acampamentos e assentamentos. $\mathrm{O}$ artigo é resultado de um estudo de caso, desenvolvido no Acampamento Sem Terra, denominado de Dalcídio Jurandir, localizado no Sudeste Paraense e encaminhado por uma abordagem qualitativa. Entende-se que o movimento social busca uma educação que dê conta de compreender as circunstâncias vividas a partir de suas contradições sociais, tendo a mesma lógica de resistência do campesinato, porque é nele que ela tem sua raiz histórica. Trata-se de uma educação que antecede à escola e vai muito além dela.

Palavras-chave: Educação; Luta pela Terra; Resistência Camponesa.

\section{ABSTRACT}

This article is the result of the master's research notes developed in the Postgraduate Program in Amazon Agriculture (PPGAA) of the Federal University of Pará - UFPA. It addresses the challenges of the struggle for land in Southeast Pará, reflecting on the role of education in this process. This paper points out the education that permeates people's daily lives, as an element that strengthens the political resistance of the peasants, therefore, it is not only related to the conquest of the land, but also to the permanence in it and to the change in the quality of life in the encampments and settlements. The article is the result of a case study, developed at the agrarian reform camp, called Dalcídio Jurandir, located in Southeast Pará and guided by a qualitative approach. It is understood that the social movement seeks an education that is able to understand 
|Chirles da Silva Monteiro | Gutemberg Armando Diniz Guerra |

the circumstances experienced from its social contradictions, having the same logic of resistance as the peasantry, because it has its historical roots in it. It is an education that precedes school and goes far beyond it.

Keywords: Education; Struggle for Land; Peasant Resistance.

\section{RESUMEN}

Este artículo es el resultado de las notas de investigación de maestría desarrolladas en el Programa de Posgrado en Agricultura Amazónica (PPGAA) de la Universidad Federal de Pará - UFPA. Aborda los desafíos de la lucha por la tierra en el sureste de Pará, reflexionando sobre el papel de la educación en este proceso. Señala la educación que permea la vida cotidiana de las personas, como un elemento que fortalece la resistencia política de los campesinos, por lo tanto, no solo se relaciona con la conquista de la tierra, sino también con la permanencia en ella y con el cambio de la tierra. Calidad de vida en los campamentos y asentamientos. El artículo es el resultado de un estudio de caso, desarrollado en el Campamento Sem Terra, llamado Dalcídio Jurandir, ubicado en el sureste de Pará y guiado por un enfoque cualitativo. Se entiende que el movimiento social busca una educación que sea capaz de comprender las circunstancias vividas desde sus contradicciones sociales, teniendo la misma lógica de resistencia que el campesinado, porque tiene en ella sus raíces históricas. Es una educación que precede a la escuela y la va mucho más allá.

Palabras clave: Educación; Lucha por la Tierra; Resistencia Campesina.

\section{INTRODUÇÃO}

Este artigo versa sobre a relação entre educação e a luta pela terra no Sudeste Paraense. $\mathrm{O}$ estudo foi feito na tentativa de compreender os sentidos atribuídos à educação pelos camponeses que lutam pela terra na região. À medida que os camponeses foram se organizando, a região do Sudeste do Pará foi sofrendo transformação na sua estrutura fundiária. A disputa pela terra gerou conflitos que perduram, caracterizando a região como a área de maior pressão social do Estado.

A mobilização dos sujeitos em torno da sindicalização foi fundamental para os enfrentamentos que levaram a eclodir conflitos em várias áreas no Sudeste do Pará. A mobilização dos camponeses da região se deu via os Sindicatos de Trabalhadores Rurais (STR's), Movimento dos Trabalhadores e Trabalhadoras Sem Terra (MST) e Federação dos Trabalhadores na Agricultura (FETAGRI) (VEIGA et al., 2006). Os conflitos agrários que ali foram se estabelecendo atraíram instituições que atuaram e atuam no apoio e na defesa dos camponeses, como Universidade Federal do Pará (UFPA), Comissão Pastoral da Terra (CPT), Sociedade Paraense de Defesa dos Direitos Humanos (SPDDH) e instigou a criação de outras como a Superintendência do Instituto Nacional de Reforma Agrária (INCRASR/27), criada em 1996 após o Massacre de Eldorado do Carajás com o objetivo de mediar e resolver os conflitos agrários na região.

É nesse ambiente de luta pela terra e pela condição de camponês, que famílias se reuniram no acampamento Dalcídio Jurandir, no município de Eldorado dos Carajás no 
|Chirles da Silva Monteiro | Gutemberg Armando Diniz Guerra |

Sudeste do Estado do Pará, reivindicando a posse da terra, elemento essencial para sua reprodução. A luta não se esgota com o acesso à terra, pois, as condições elementares para permanecer na mesma com dignidade, também são parte de uma busca constante, que requer organização, ação coletiva e resiliência.

Este trabalho procurou extrair de dentro da vida dos camponeses acampados, com toda sua trama de relações, situações educativas, que devem ser levadas em conta na formação do campesinato local, assim como extrair as visões e os sentidos que os sujeitos foram dando à educação, na sua mais variada vertente, em particular no momento crítico de pressão sociopolítica que é o acampamento. Tomamos o entendimento de educação, na perspectiva de Brandão (2007), como cultura; e sob o ponto de vista de Freire (2011), como ação cultural para a liberdade, ação esta que se dá no confronto de duas pedagogias: a do opressor e a do oprimido.

Desde a segunda metade do século passado, o Brasil passou por profundas transformações no campo, traduzida como "Revolução Verde". Os impactos recaídos sobre a estrutura agrária foram imensos, com o padrão tecnológico da agricultura e as relações sociais de produção se alterando, o que suscitou a expulsão de milhares de camponeses de suas áreas. Tudo isso agravou as tensões sociais que resultou na eclosão de conflitos agrários e no surgimento de movimentos sociais no campo (MARTINS, 1991; SILVA, 1982). O fato é que toda essa complexidade no campo contribuiu para reacender o debate sobre a questão agrária brasileira e sobre o destino do campesinato no desenvolvimento capitalista. Muitos estudiosos têm se preocupado com essa questão, uns fortalecendo a tese do fim do campesinato (KAUTSKY, 1986), outros defendendo a ideia da resistência e recriação camponesa (HÉBETTE, 2004; GUERRA, 1999). Corroboramos com estes últimos, por compreendermos que nessa trajetória de confrontos no campo, os camponeses foram criando caminhos que têm configurado a sua resistência, e a educação é um desses elementos.

A luta pela terra pressupõe a efetivação do direito à terra. Quando se criou o movimento por educação no meio de um movimento social, foi por compreender que essa luta não se esgota com a conquista da terra. Segundo Carvalho (2002, p. 246), "as lutas por terra foram sendo gradativamente ampliadas para políticas públicas, e foi aos poucos consolidando a identidade social de resistência dos sujeitos" e ao mesmo tempo construindo outra visão - a de solidariedade, de construções coletivas. Compreender como a educação se insere nesse processo de construção é o elemento focal desse artigo.

O interesse por essa temática no Sudeste Paraense, Amazônia Brasileira, partiu da necessidade de entender a conjuntura político-agrária-educacional desse território, onde 
| Chirles da Silva Monteiro | Gutemberg Armando Diniz Guerra |

camponeses se unem para pressionar o governo a fazer reforma agrária e, como estratégia de visibilidade político-social, acampam nas proximidades da terra reivindicada ou em órgãos públicos. Segundo Ferreira (2018), existem 473 assentamentos rurais no Sudeste do Pará. Essa região tem uma representatividade no que concerne ao volume dos problemas fundiários em relação a todo o país, por ter uma atuação efetiva do Movimento dos Trabalhadores Rurais Sem Terra e dos Sindicatos dos Trabalhadores Rurais, e por haver uma prática de Educação do Campo sendo realizada pela Universidade Federal do Pará, Instituto Federal do Pará e uma demanda do movimento social por esta perspectiva de educação.

A resistência política desses camponeses visa garantir a sua manutenção e reprodução enquanto categoria social, contrariando ao movimento do capital e as tendências teóricas que preveem o seu desaparecimento. Ela está relacionada aos projetos de desenvolvimento que se instalaram na região, e os tem deixado à margem dos benefícios desse processo.

Buscou-se compreender quais os sentidos da educação pleiteada por esses sujeitos campesinos e se esta tem fortalecido a resistência política camponesa, entendida como aquela que se expressa como manutenção e reprodução social, que "resiste à expropriação" (MARTINS, 1991), que busca melhorar suas condições de vida, mas que não quer sair do campo. Desta forma, a resistência política tratada neste trabalho não está relacionada apenas à conquista da terra, mas também, à permanência na mesma e à mudança da qualidade de vida nos acampamentos e assentamentos. Trata-se de manter-se na terra como elemento produtivo e como lugar de moradia, de produção cultural, de um estilo de vida que tem relação com a valorização da natureza e sua resiliência humana. Contudo, em que medida a educação fornece elemento para fortalecer essa resistência política camponesa foi uma das inquisições deste artigo.

Há uma demanda do movimento social camponês, por um modelo de educação adequado aos nossos tempos, em que o campesinato tem demostrado sua capacidade de se expressar e se impor enquanto categoria social. Em que pese o esforço das instituições de ensino e do movimento social, e dos avanços nessa área, a demanda continua não atendida.

Existe uma lacuna sobre o tema, motivo pelo qual destacamos a sua relevância, sendo importante compreender qual o sentido que tem sido dado a esta educação e se suas práticas tem se configurado em elemento de resistência política para permanência na terra disputada por esses camponeses.

Nesse artigo priorizou-se o enfoque qualitativo, por entender que ele favorece uma análise densa das questões abordadas. 
|Chirles da Silva Monteiro | Gutemberg Armando Diniz Guerra |

A análise histórica analítica e interpretativa foi feita confrontando os dados oriundos das entrevistas, narrativas e da observação direta, com os dados expressos nas bibliografias e nos discursos consolidados. Ao analisar esses dados recorreu-se inúmeras vezes às anotações feitas no caderno de campo, procurando relembrar eventos concebidos no ato das entrevistas e durante a vivência com as famílias no acampamento.

\section{A HiSTORICIDADE DA LUTA PELA TERRA E PELA EDUCAÇÃo}

Hébette (2004, p. 195), estudando o campesinato no Sudeste do Pará, concluiu que "o camponês aprende no cotidiano, na prática da luta". Ainda segundo suas análises, "a sindicalização dos sujeitos forjou um processo educativo oriundo das interações na luta pela terra". Compreendemos aqui esse processo educativo oriundo dos movimentos sociais como este, que desabrocha em lugares áridos e direcionam para construção de um novo sujeito, que a partir da leitura sobre a sua realidade consegue pensar novas estratégias e projetar novos caminhos.

Caldart (2009) assinala que os primeiros Sem Terra, do Sul do Brasil, não apontaram a educação como elemento contribuinte para a participação no movimento. As lembranças que remetiam à escola eram tristes, de um lugar de exclusão. Segundo a autora, a educação passa a ser pleiteada pelo movimento, a partir da consciência de que a luta pela terra e a luta pela educação não eram processos separados (CALDART, 2009).

Embora a autora destaque que a educação não tenha sido fator impulsionador que levara os camponeses a se organizar e participar dos movimentos sociais, por outro lado, ela sempre esteve presente nos projetos sociais dos movimentos camponeses. Desde as ligas camponesas já se questionava o modelo de educação, e apontava para a democratização da mesma, pensada dentro de seus contrastes sociais.

Com a criação dos acampamentos e assentamentos, explicitou-se que não podiam negar mais esse direito aos sujeitos, o direito à educação, garantido na Constituição Federal de 1988 (CALDART, 2012). O quantitativo de crianças nos acampamentos e assentamentos determinou a luta pela garantia da escola. Dessa forma conjugaram-se a luta pela terra, reforma agrária e transformação social e, com isso, estabeleceu-se um rumo, que permitiu que se construísse uma organicidade, em que vários outros assuntos se incorporassem dentro da pauta do movimento social. Entende-se que não se tem como avançar com o processo de transformação social sem avançar na perspectiva da educação. Se a educação não foi elemento determinante na decisão dos sujeitos em participar do 
|Chirles da Silva Monteiro | Gutemberg Armando Diniz Guerra |

movimento, por outro lado, o envolvimento no movimento foi determinante para perceber a importância da educação no processo da luta pela terra.

No bojo do movimento camponês na luta pela terra identificou-se a educação como estratégia, e historicamente ela se tem feito presente em proporção e dimensões amplas. Luta pela terra e educação caminham juntas. Só se constrói educação porque tem um processo de luta e um rumo estabelecido. E a educação é parte disso, porque ela permite a qualificação, a capacitação que vai qualificando o movimento, dentro da dialética que conjuga: luta, educação e conquistas. A educação é um direito e, para tal, precisam-se criar instrumentos para que ela ocorra.

É convicção do Movimento Social que é preciso investir na educação, não apenas na educação formal, mas para além das escolas. A escolarização é posta como fundamental, mas o movimento não compreende a escola como único lugar do aprendizado. Este se faz em vários espaços, e é visto por excelência como conhecimentos válidos para a construção do cidadão consciente de seu papel social.

Esses princípios de educação penetraram nos movimentos sociais camponeses e foram gradativamente sendo assimilados pelos sujeitos, a ideia de uma educação libertária e emancipadora $^{1}$, e passa a ser pensado no seio do movimento um modelo de educação que traga esses princípios implícitos em seu formato de projeto educacional, para as demandas campesinas. As péssimas recordações da escola que tinham os que passaram por ela, agora podiam vislumbrar uma escola diferente para seus filhos, onde não fossem excluídos dela, mas que dialogassem suas histórias de vida e sua realidade cotidiana dentro dela com os conteúdos universais da escola formal.

De acordo com Brandão (2007, p. 11), “a força da educação consiste em ajudar a pensar tipos de homens, legitimando saberes que envolvem troca de símbolos, produção de crenças e ideias". Essa essência é apropriada pelo MST, que tem por excelência todos os espaços de luta e organização como lugares de aprendizados. Pensam na formação dos seus sujeitos enquanto sujeito social em movimento. A educação do MST visa fortalecer o movimento, construindo sujeitos conscientes social e politicamente, para construir um projeto social em que as injustiças e as desigualdades sejam superadas, se não, amenizadas.

Nos movimentos sociais do campo, o espaço educacional não é apenas a escola. Ele é o lugar da vida e do trabalho, compreendidos como: o barraco, a roça, as reuniões, a igreja, as formações, os congressos, os encontros, e outros. Todo lugar onde a vida se encontra é lugar de aprendizado. Conhecimentos diversos circulam e são assimilados por outros como medicinais, culinária, históricos, geográficos, políticos, religiosos, e tantos

${ }^{1}$ Expressão usada a partir das leituras de Freire (1987-2011). 
outros, locais e globais, vão fazendo parte do acervo dos saberes dos grupos participantes dos movimentos.

\section{A DIMENSÃO EDUCACIONAL DO ACAMPAMENTO}

A escolha em fazer uma abordagem a partir do acampamento é por compreender que o movimento sindical tem uma forma de educação e de resistência política que atravessa todas as fases e o acampamento é um momento em que aparecem mais claramente estes elementos de resistência. É um momento no qual está aflorado o espírito de coletividade e solidariedade das pessoas, há uma esperança que os move a trabalhar juntos na perspectiva de alcançar esse ideal coletivo: a terra.

A esperança é alimentada através das místicas, das músicas, das leituras, da bandeira, que tem o poder de entranhar nas pessoas e de alinhar os sujeitos em torno de uma identidade sem terra. Na visão de Giddens (1991, citado por SCHMITZ, 2009, p. 15), “o acampamento é um lugar privilegiado de alinhamento, pois os sem terra passam por um processo de desencaixe e depois de um reencaixe quando conquistam o assentamento". Entender como a educação se materializa nessas condições é um desafio que requer uma apropriação de termos teóricos e de sistematização dialogada com a prática dos atores sociais, nos seus cotidianos.

No acampamento, talvez pelo fato de as pessoas estarem mais próximas, ocasionadas pelos anos no convívio constante, essa troca de conhecimento é explícita. A dimensão da realidade é percebida pelas pessoas, o confronto de lutas de classes e o entendimento das mesmas, são magnificentes, pois a firmeza com que pessoas 'analfabetas' discursam sobre a necessidade da luta e união de todos para o enfrentamento, para conquistar a terra, para garantir posteriormente a permanência das famílias nos lotes, é embasado em princípios filosóficos e sociais. E esse conhecimento é adquirido na participação e nos ensinamentos dos movimentos.

A cada jornada vivida por esses grupos camponeses paira a incerteza, o medo, a esperança. Todos esses sentimentos podem ser percebidos nos semblantes das pessoas e nas conversas posteriores. Ele traz à memória lembranças de outros momentos fatídicos e também de momentos de conquistas. Todos sabem o motivo da jornada, as crianças não participam de forma alheia, o seu olhar expressa bem o motivo pela qual está ali. Nenhum brinquedo está à beira da estrada, quando esta está sendo bloqueada, nas mãos portam uma bandeira do MST e na cabeça um boné. Os símbolos da consciência de sua presença naquele espaço. 
| Chirles da Silva Monteiro | Gutemberg Armando Diniz Guerra |

Questionar se a infância não está sendo roubada, se a inocência do mundo colorido não está, muito cedo, sendo substituída por um mundo cinza, incerto e cheio de dúvidas é excluí-las, tirar delas a sua participação nesse processo. Negar a realidade não faz parte da educação do MST às suas crianças. Antes, apresenta-a como ela é, com suas mazelas e desafios, e projetam o futuro a ser alcançado, com base na luta constante, capaz de recriar a realidade vivida.

Desta forma, tendo em vista formar um perfil de cidadão com consciência de classe e lutador, é que os movimentos sociais do campo têm a convicção que a educação não é neutra. Freire alertava sobre isso, e passaram a levantar com maior veemência a bandeira da educação, culminando no Movimento Nacional de Educação do Campo.

A educação não pode desvincular-se da luta, da realidade cotidiana, do trabalho e da cultura camponesa. Assumir a educação como direito de todo cidadão e como dever do Estado significou avanços, pois a luta passou a ser estruturada dentro dessa concepção de direito (ARROYO, 2007). E, nesse processo, os sujeitos passaram a reivindicar não apenas a escola, mas a transformação dessa escola. Para o MST, a escola ensina muito mais pelo jeito que ela se organiza para ensinar, do que do jeito que ensina. É desta forma que percebemos que essa luta pela educação está implícita na luta pela terra, e cria e recria o campesinato em formação no Sudeste do Pará.

$\mathrm{Na}$ defesa do direito dos povos do campo à educação, os movimentos sociais têm colocado que o território, a terra, a cultura, a educação e os processos de produção da terra são elementos que se articulam e caminham juntos na mesma luta. A formação do homem do campo não se faz de forma fragmentada. Primeiro busca-se a terra, a raiz que faz com que a materialização dos demais elementos sejam possíveis. Arroyo (2007), analisando o percurso da luta dos movimentos sociais pelo direito à educação, concluiu que:

\begin{abstract}
Os movimentos sociais revelam e afirmam os vínculos inseparáveis entre educação, socialização, sociabilidade, identidade, cultura, terra, território, espaço, comunidade. Uma concepção muito mais rica do que a redução do direito à educação, ao ensino, informação que pode ser adquirida em qualquer lugar. Há bases teóricas profundas, inspiradas nas concepções da teoria pedagógica mais sólida, nesses vínculos que os movimentos sociais do campo defendem entre direito à educação, à cultura, à identidade e ao território. Dimensões esquecidas e que os movimentos sociais recuperam (ARROYO, 2007, p. 163).
\end{abstract}

A entrada de outros movimentos sociais na defesa do direito à escolarização dos povos do campo, muitos vinculados à Federação dos Trabalhadores da Agricultura Familiar - FETRAF e à Confederação Nacional dos Trabalhadores da Agricultura CONTAG ajudou a ampliar a consciência do direito à educação: da reivindicação da escola ampliou para reivindicação de educação de qualidade, para o entendimento de que não é 
|Chirles da Silva Monteiro | Gutemberg Armando Diniz Guerra |

qualquer educação que serve. Ela precisa ser para valorizar a identidade dos sujeitos do campo, valorizar suas lutas, valorizar sua produção, valorizar sua humanização. É com esse entendimento de educação que os povos do campo do Sudeste do Pará têm pautado suas reivindicações.

O MST tem colocado como prioridade a garantia da educação desde o acampamento ao assentamento. Ao erguer um acampamento, logo é providenciada "a escola" debaixo de lona ou debaixo de um barracão improvisado. As crianças retomam, para algumas, iniciam pela primeira vez, suas atividades escolares. Ao fazer uma ocupação os sujeitos estão mostrando para a sociedade que quer aquela terra, porque precisam de um lugar para viver. Mas, não precisam apenas da terra. O MST trabalha na perspectiva de erradicar o analfabetismo, atua rompendo com a posição que a burguesia impôs de que os trabalhadores do campo não precisam aprender a ler. A presença da escola no acampamento traz essa simbologia, pois é convicção do movimento social que é essencial investir na educação, e esta não está centrada na escola, está presente em todos os processos de luta do movimento. Existe também o problema legal, que é permitir que a criança que vem para o acampamento não perca aula. A construção da escola no acampamento tem vários sentidos, entre estes o sentido da resistência. Famílias inteiras vêm para o acampamento e sua permanência se deve a vários fatores, e a escola é um desses.

Muitos vivem aqui no acampamento porque tem a escola, senão já teriam ido embora, para a casa de parentes, procurar lugar para os seus filhos estudarem (Márcia, professora do Acampamento, entrevistada em julho de 2014).

O papel agregário de escola e de ensino praticado nas condições do acampamento dá liga às relações de solidariedade que se tornam necessárias neste momento de disputa jurídica pela terra.

Se não tivéssemos a escola não estaríamos mais na luta; se estivéssemos, com certeza ela estaria enfraquecida. Porque a maioria das familias já teria ido embora, afinal são anos aqui, e a escola é a nossa maior arma para resistir nessa luta (Luiz, professor, acampado, entrevistado em julho de 2014).

Certamente que as lições de resistências e persistências são conteúdos concretos que originam a atividade de ensino nestes lugares.

A escola é o coração do nosso acampamento; é o que dá vida ao lugar. Se continuamos nessa luta éporque temos uma escola onde nossas crianças possam aprender. Não só nossas crianças, jovens e adultos aprenderam a ler aqui... Vieram da cidade e foi no acampamento que aprenderam a ler. Coisa até engraşada, mas é a verdade. Eu diria que a escola é o nosso maior 
|Chirles da Silva Monteiro | Gutemberg Armando Diniz Guerra |

símbolo de resistência do acampamento (Esmerina, acampada desde 2008, entrevistada em dezembro de 2014).

Os produtos desse momento se materializam no aprender a ler que se expressa como gesto fundamental, essencial, visceral do cidadão. E mais do que isso, é instrumento de reconhecimento do espaço como território, lugares de vida, simbolizado pela institucionalidade mínima que uma escola dá ao ambiente social.

Hoje, eu vejo que uma das bases que mantém o movimento vivo aqui é a escola. Sem ela nós já teríamos fraquejado. Ela é nossa arma de pressão também (José Rubens, Diretor da escola, acampado desde 2009, entrevistado em Outubro de 2013).

Se a escola se constitui como elemento de resistência no processo de luta pela terra, ela deve caminhar na perspectiva do que Scherer-Warren (2000, p. 25) coloca, isto é, “em sintonia com as forças culturais e sinérgicas de cada realidade social, assim como os atores dos movimentos devem estar atentos ao que se lhes propõe como aprendizado". Compreende-se que a escola tem o sentido da resistência no acampamento não apenas pelo conteúdo que ela ensina, mas pelo fato dela existir. Ela é uma 'arma de pressão', para dentro do acampamento, porque esse laço de solidariedade favorece a reflexão e o posicionamento amadurecido pelo pensamento lógico, e para fora, pois dá foro de cidadania aos acampados. Quando a paralização da escola ocorre em função de jornadas organizadas pelo Movimento, que na maioria das vezes envolve outros acampamentos e assentamentos, as aulas não são repostas, pois os alunos recebem aulas nos locais onde estão sendo ocupados. Os professores se organizam, para atender os alunos nas cirandas. O conteúdo é flexível, são realizadas atividades lúdicas e de reflexão ao momento vivido. As crianças e jovens recebem esclarecimentos, do motivo da ocupação e porque ela é necessária, cada um segundo sua mentalidade (crianças e jovens). Os textos, as atividades, as músicas, as místicas, são elementos trabalhados para esse entendimento e reflexão. A escola do acampamento é vista pela literatura como escola itinerante, porque de fato ela tem esse caráter, essa dimensão de acompanhar a dinâmica do movimento.

É em torno da escola, no acampamento Dalcídio Jurandir, que todas as atividades desenvolvidas no acampamento e mesmo fora dele se estruturam. Sobre ela não paira o olhar apenas da escolarização dos filhos, mas o 'porto seguro' da luta naquele lugar. Ela é vista por muitas vertentes, e cada olhar do sujeito sobre ela tece uma singularidade no seu sentido de existência ali. 
|Chirles da Silva Monteiro | Gutemberg Armando Diniz Guerra |

A escola adquire o sentido da resistência no processo de luta pela terra, na fase do acampamento, porque ela é o fator determinante que assegura a permanência das famílias. Durante tantos anos, "se não houvesse a escola, as famílias já teriam abandonado o acampamento"; essa é a frase reificada pelos sujeitos.

Em contrapartida, quando perguntados sobre onde mais se aprende no acampamento, as respostas não indicam a escola como lugar determinante do aprendizado, os sujeitos concebem o movimento como lugar de práticas educativas. Todos os espaços foram apontados como lugar de educação: formações, jornadas, encontros, a convivência cotidiana no acampamento, a escola, os grupos de base, o local de lazer, a igreja, etc. Todos esses espaços são denominados pelos camponeses como lugares em que se aprende e ensina. Caldart (2012) indica que “o educador principal é o movimento, que educa os sujeitos enraizando-os em uma coletividade forte, e pondo-os em movimento na luta pela sua própria humanidade" (CALDART, 2012, p. 23).

De acordo com Scott, Menezes e Guerra (2002, p. 12), a resistência camponesa pode ser de duas ordens: a "resistência passiva" e a "resistência de confrontação direta". Segundo o autor, a resistência passiva é sorrateira, acontece sutilmente e não produzem manchetes nos jornais. Por outro lado, a resistência de confrontação tira os sujeitos do anonimato, está agregada aos motins, a ocupações de espaços, com vistas a suprir uma necessidade imediata do grupo. Segundo o autor, essas formas de resistência se manifestam mediante as características singulares do campesinato.

Se tomarmos o acampamento como exemplo, ele se encaixa em um modelo de resistência de confronto direto, os sujeitos ocupam a terra, para dizer para a sociedade geral e para o poder público que precisam de uma terra para cultivar e viver. O corte no arame que rompe a cerca, a elevação dos barracos, o confronto com a polícia e/ou jagunços, tudo isso exemplifica uma resistência de confronto direto. Por outro lado, em relação à resistência passiva, apontada pelo autor, também é vivenciada pelos acampados.

Em relação aos sentidos que os acampados atribuíram à educação na fase do acampamento, suas respostas abriram-nos um leque de interpretações, na qual uma não anula a existência da outra, mas são percebidas de maneiras diversas pelos camponeses. $O$ gráfico a seguir foi elaborado com base nas narrativas das pessoas acampadas, entre elas, professores, alunos, pais e lideranças. Representa os sentidos que as pessoas atribuem à educação no Dalcídio Jurandir. A partir de suas interpretações foi necessário fazer um mapeamento, para que assim pudéssemos analisar e refletir de forma sistemática. 
|Chirles da Silva Monteiro | Gutemberg Armando Diniz Guerra |

Gráfico 1 - Mapeamento dos sentidos e significados atribuídos à educação na luta pela terra



Fonte: Pesquisa de campo, 2013-2017. ${ }^{2}$

Embora apontem vários sentidos para a educação na relação da luta pela terra, a resistência é preponderante. Em todos os grupos de entrevistados ela é destacada como elemento intrínseco à educação nesse momento de defesa da reforma agrária.

Ao apontar a educação como elemento determinante de resistência na luta pela terra, durante a fase do acampamento, os sujeitos se apoderam de uma forma de resistir que não está em confronto direto, mas que os firmam no dia a dia do acampamento.

A resistência dos camponeses é contra um sistema que outrora os expropriou de suas terras. Resistem para se manterem vivos como classe, que tem a terra como elemento fundamental da reprodução de sua família e o trabalho desta como mão de obra de sua reprodução camponesa. Para Martins (1991), os sujeitos resistem porque eles foram excluídos, expropriados e explorados; é contra essa condição de "ficar de fora", à mercê de uma vida miserável, que os sujeitos se organizam, somam suas forças e resistem, para assegurar sua humanização, e desta forma têm se colocado, mediante a luta, como sujeitos políticos e de direitos.

Hébette (1989) coloca que a resistência dos camponeses é para permanecer na terra ou para lutar contra a expropriação. E para isso o caminho viável é a organização. Só por meio dela, os camponeses teriam a força necessária para lutar contra a expropriação. Uma

\footnotetext{
2 Os dados do gráfico são referentes às informações colhidas em entrevistas (40 pessoas) do acampamento Dalcídio Jurandir, nos anos de 2013-2017.
} 
|Chirles da Silva Monteiro | Gutemberg Armando Diniz Guerra |

vez expropriados, a luta dos camponeses é para retornar à terra. Esse retomar das origens campesinas significa o retorno ao 'eldorado', é a conquista do lugar para 'descansar os pés', cansados de tanto vagar em busca da terra, para plantar e criar os filhos.

E se nesse processo a educação é identificada como estratégia de resistência, não é por acaso, pois ela encontra-se entranhada nos movimentos, não apenas no MST, mas em todos que levantam a bandeira da justiça social e da igualdade de direitos. No caso do MST, a educação é tida como um processo permanente de formação humana, do qual a escola faz parte. De acordo com Scott, Menezes e Guerra (2002, p. 11), para os camponeses, explorados ao longo do tempo, e que enfrenta muitos obstáculos para se organizar, as formas cotidianas de resistência são particularmente importantes. Assim, compreendemos, pela racionalidade colocada pelos acampados, como a educação se configurou nessa perspectiva de resistência, como aquela que habita nas dimensões particulares do grupo, assim como nas gerais, quando os sujeitos levantam a bandeira de uma perspectiva educacional que passa a reivindicar uma educação para os povos do campo, que dialogue saberes populares, científicos e que valorize a luta e a organização dos camponeses.

\section{CONSIDERAÇÕES FINAIS}

O avanço do capital sobre o campo tem provocado choro, mortes, miséria, violência e injustiça. Nesse antagonismo sócio-político-econômico, não restou outra saída aos camponeses a não ser o caminho de resistir contra o processo de expulsão que foi instalado no campo brasileiro. Para tal, as pessoas foram construindo suas organizações, juntando forças para reivindicar seus direitos, assim como para fazer valer suas próprias concepções de direitos.

O artigo estruturou-se pela hipótese de que a luta pela terra no Sudeste do Pará identificou a educação como estratégia de resistência, configurando-a em elemento importante da reprodução do campesinato, na medida em que é pensada e trabalhada a partir da perspectiva da participação, organização, autonomia, democracia e cidadania dos camponeses. A partir da análise desenvolvida, acredita-se ter chegado a um bom termo no artigo.

Se por um lado, as narrativas apontam o sentido da resistência inserido na educação, que perpassa todos os espaços de convívio das pessoas engajadas na defesa da reforma agrária na região, por outro, percebe-se que o diálogo com os sujeitos da base da organização social precisa ser mais aproximado, para que assim possa consolidar uma 
|Chirles da Silva Monteiro | Gutemberg Armando Diniz Guerra |

proposta maior, de um projeto que está em disputa no meio rural no qual o camponês é o protagonista principal dessa bandeira.

A partir das narrativas de histórias de vida e da análise desenvolvida, buscou-se evidenciar como o sentido da educação foi recriado pelos camponeses acampados a partir de sua inserção no movimento social. Se antes educação e trabalho eram vistos como antagonismo, por um inibir a execução do outro, agora passam a ser compreendidos como atividades que devem dialogar e coexistirem. Se ao homem do campo bastava apenas aprender a escrever o nome, agora se percebem como sujeitos de direitos, que pleiteiam a educação como parte de sua formação humana, que deve ser ofertada no contexto da sua vida e que serve para fortalecer a causa camponesa.

Nestas considerações finais destacamos que os Movimentos Sociais que lutam pela terra no Sudeste do Pará tem que enfrentar grandes desafios em suas práticas pedagógicas, para fortalecer a sua identidade, a resistência e avançar no processo de territorialização do camponês e da educação. Para isso, é necessário retomar o diálogo e decisões com suas bases sem negligenciar suas opiniões, seus saberes e seus contrates. A força do movimento social camponês está nessa ligação próxima das lideranças com sua base. Se essa corrente se rompe, compromete a marcha da reforma agrária que está centrada na história, no trabalho, no sonho e na utopia de cada pessoa que abraça essa causa social.

A educação forjada a partir da luta cotidiana dos acampados é como cimento, estratégia criada para fortalecer o grupo evitando sua fragmentação. Ela é um instrumento de consciência política na medida em que contribui para a compreensão de classes sociais e antagonismos socioeconômicos. A participação no movimento social camponês insere o sujeito no campo de caráter educativo e emancipatório. A realidade passa a ser repensada a partir das condições históricas e uma consciência crítica começa a ser construída.

Os resultados mostram o entendimento de que a inserção da educação no contexto da luta pela terra é percebida de forma diversa pelos camponeses. A ela são atribuídos vários sentidos e significados que se complementam na compreensão do fortalecimento da luta pela reforma agrária, levando-os a resistirem diante de um processo reiterativo de expulsão e de negação dos direitos de cidadania. Conclui-se então que é por entre a narrativa, a luta, a educação, o trabalho e o sonho, que a história do campesinato continua e resiste na Amazônia Paraense.

\section{REFERÊNCIAS}


| Chirles da Silva Monteiro | Gutemberg Armando Diniz Guerra |

ARrOYO, Miguel Gonzáles. Política de Formação de Educadores (as) do Campo. Cad. Cedes, Campinas, v. 27, n. 72, p. 157-176, maio/ago. 2007. Disponível em: $<$ http://www.cedes.unicamp.br>. Acesso em: 30 mar. 2015.

BRANDÃO, Carlos Rodrigues. O que é Educação. São Paulo: Brasiliense, 2007.

CALDART, Roseli Salete. Pedagogia do Movimento Sem Terra. 4. ed. São Paulo: Expressão Popular, 2012.

CALDART, Roseli Salete. A escola do campo em movimento. In: ARROYO, Miguel Gonzáles; CALDART, Roseli Salete; MOLINA, Mônica Castagna (Org.). Por Uma Educação do Campo. 4. ed. Petrópolis, RJ: Vozes, 2009. p. 89-128.

CARVALHO, Horácio Martins. A emancipação do movimento no movimento de emancipação social continuada (resposta a Zander Navarro). In: SANTOS, Boaventura de Sousa (Org.). Produzir para viver: os caminhos da produção não capitalista. Rio de Janeiro: Civilização Brasileira, 2002. p. 233-260.

FERREIRA, Gustavo Henrique Cepolini. A obra cinematográfica de Adrian Cowell: legado de resistência e territorialidades para a Amazônia. 2018. 526 f. Tese (Doutorado em Geografia Humana) - Universidade de São Paulo, São Paulo, 2018. Disponível em:

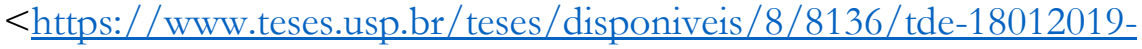

145512/publico/2018 GustavoHenriqueCepoliniFerreira VOrig.pdf >. Acesso em: 19 jun. 2021.

FREIRE, Paulo. Educação como prática da liberdade. 14. ed. rev. atual. Rio de Janeiro: Paz e Terra, 2011.

HÉBETTE, Jean. A resistência dos posseiros. Travessias - revista do migrante, São Paulo: CEM, n. 3, p. 15-18, jan./abr. 1989.

HEBETTE, Jean. A resistência dos posseiros. In: Cruzando a Fronteira: 30 anos de estudo do campesinato na Amazônia. Belém: EDUFPA, 2004. v. 02.

KAUTSKY, Karl. A Questão Agrária. São Paulo: Nova Cultural, 1986.

MARTINS, José de Souza. Expropriação e violência: a questão política no campo. 3. edição, São Paulo: Hucitec, 1991.

SCHMITZ, Heribert. O MST à luz de teorias dos movimentos sociais. In: CONGRESSO BRASILEIRO DE SOCIOLOGIA, 14., 2009, Rio de Janeiro. Anais... "Sociologia: Consensos e Controvérsias”. Rio de Janeiro: SBS, 2009.

SCOTT, James C.; MENEZES, Marilda A. de; GUERRA, Lemuel. Formas cotidianas de resistência camponesa. Raízes, Campina Grande, v. 21, n. 01, p. 10-31, jan./jun. 2002.

SILVA, José Graziano da. A modernização dolorosa: estrutura agrária, fronteira agrícola e trabalhadores rurais no Brasil. Rio de Janeiro: Zahar Editores, 1982.

VEIGA, Iran; OLIVEIRA, Myriam C. de.; BENTES, Francinei. Políticas públicas e dinâmicas locais da agricultura familiar no sul e sudeste do Pará. In: TONNEAU, J. P.; 
SABOURIN, Eric (Org.). Agricultura familiar, políticas públicas e dinâmicas locais. Porto Alegre: Ed. UFRGS, 2006.

\section{Como citar:}

\section{ABNT}

MONTEIRO, C. S.; GUERRA, G. A. D. Educação e resistência camponesa na Amazônia paraense. InterEspaço: Revista de Geografia e Interdisciplinaridade, v. 7, e202127, 2021. Disponível em: <http://dx.doi.org/10.18764/2446-6549.e202127>. Acesso em: 11 out. 2021.

\section{APA}

Monteiro, C. S.; \& Guerra, G. A. D. Educação e resistência camponesa na Amazônia paraense. InterEspaço: Revista de Geografia e Interdisciplinaridade, v. 7, e202127. Recuperado em 11 outubro, 2021, de http://dx.doi.org/10.18764/2446-6549.e202127

\section{@creative}

This is an open access article under the CC BY Creative Commons 4.0 license.

Copyright (C) 2021, Universidade Federal do Maranhão.

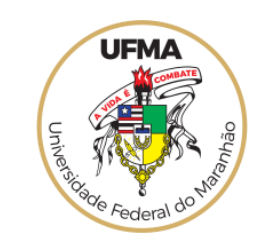

